\title{
THE EFFECTIVENESS OF DECONVOLUTION PROCESS IN PRESENCE OF RANDOM NOISE ON THE BASE OF ROCK SALT DEPOSITS FROM "BYTOM ODRZAŃSKI” AREA
}

\author{
EWA KaWALEC-LATAŁa \\ Department of Geophysics, AGH University of Science and Technology, \\ al. Mickiewicza 30, 30-059 Kraków. \\ Tel.: +48 1261723 43, e-mail: ewal@geol.agh.edu.pl
}

\begin{abstract}
A number of synthetic pseudoacoustic impedance sections are presented in order to test the effectiveness of deconvolution process when random noise distorted the seismic traces. A simplified seismological model is created on the basis of geological data from Bytom Odrzański area in NW part of the Legnica-Głogów Copper District (LGOM). The synthetic sections are constructed for different noise levels. Acoustic impedance is one of the basic factors characterising physical features of rocks. The main idea is the inversion of seismic sections into pseudoacoustic impedance sections. All inhomogeneities of salt deposits must be predicted before the underground storage location is fixed. The accuracy and reliability of interpretation decreases when the noise in seismic data increases. It should be realised that the inversion procedure is not a unique process. So, modelling pseudoacoustic impedance sections is recommended for verification of the effectiveness of deconvolution process for the accuracy and reliability interpretation.
\end{abstract}

\section{INTRODUCTION}

Underground reservoirs are very interesting as the objects for storage of wastes and hydrocarbons. In salt deposits there are favourable conditions for construction of such reservoirs. Zechstein rock salts of the Sudetic Monocline have been recognised within the limits of the Legnica-Głogów Copper District (LGOM).

The "Bytom Odrzański" deposits contain a set of rock salt layers. The thickness of rock salt varies. The thickness generally increases from SW to NW. An area of extremely high thickness (over $100 \mathrm{~m}$ ) of salt is most convenient for location of underground reservoir of liquid fuels or waste. Safety and reliability of energy system are one of the most important issues in dynamic development of nations and unions (UE, USA). The sequestration of $\mathrm{CO}_{2}$ to underground reservoirs will reduce its emission to the atmosphere.

Rock mass containing salt deposits displays high seismologic inhomogeneity. Inhomogeneities in geometrical sense are related to thickness changes, dying-out of strata, some inter-calculations of anhydrite within rock salt beds, presence of lenses. Many technical problems are connected with inter-calculations of anhydrite in the deposits of Zechstein evaporates within rock salt beds. Detection of anhydrite salt, occurring in the neighbourhood of rock salt in "Bytom Odrzański" deposits is necessary. The work concerns the possibility of recognising space distribution of anhydrites in the rock salt by interpretation of pseudo-impedance acoustic sections. 
Inversion of the seismic section leads to obtaining pseudoacoustic impedance sections. There are several ways this objective can be achieved [6]. That method is useful for detecting lithology changes, but in some cases visual interpretation is difficult and unpleasant. In practice, the seismic trace is always distorted by noise and wave propagation phenomena. In the case when the signal to noise ratio N/S is poor, visual interpretation is especially difficult or even impossible [1], [4].

In the paper, some examples of modelling are presented for analyzing the effectiveness of deconvolution process for the data strongly distorted by the random noise. The random noise appearing in seismic measurements is due to incorrectly fixed receiver, electric noise, transmission through the earth and the recording instruments, all the factors due to the weather, industry, traffic - generally civilization noise. It is important that the random noise is independent of time. It means that the level of noise is constant during all registration time. The energy of useful reflectivity waves strongly decreases with time. So the signal to noise ratio N/S dramatically increases with registration time. When the noise in seismic data decreases the accuracy and reliability of interpretation increases [1]). Unfortunately, a complete elimination of noise from seismic measurements is not possible. Modern seismic field data can be processed to eliminate much of the distortion. An important procedure to help repair the damage to the spectrum (caused by seismic source, transmission through the earth and the recording instruments) is deconvolution.

\section{SYNTHETIC TRACE}

The convolution model for normal incidence seismograms defines the seismic trace as convolution of the reflection coefficient series and source wavelet. Synthetic seismogram with additive noise has the form

$$
x(t)=r(t) * w(t)+n(t)
$$

where

$r(t)$ - the reflection coefficient series,

$w(t)$ - source wavelet,

$x(t)$ - synthetic trace,

$n(t)$ - additive random noise.

In a mathematical sense one must find the solution in an equation form

$$
r(t) * w(t)=x(t),
$$

which for real field data, distorted additional noise has the form

$$
r(t) * w(t)+n(t)=x(t) .
$$

Reflectivity function $r(t)$ is the required solution. 
Inversion process used the seismic trace as the reflection coefficient series. In practice the seismic trace is only its approximation additionally distorted by noise. The deconvoluted trace gives an approximation to the required reflection coefficients, the effectiveness of which is dependent upon the applicability of the basic assumptions. This is never possible in practice. Despite that, the decolvolution is one of the most effective tools for digital inversion [5].

Since complete elimination of noise from seismic measurements is not possible, it is reasonable to estimate a priori the level of noise for reliable interpretation of seismic sections. It should be realised that the inversion procedure is not a unique process. There is no single solution to the given problem. Feasibility studies with synthetic modelling of pseudoimpedance sections are recommended.

In this case, the modelling methods of pseudoimpedance acoustic sections are useful for the evaluation of the influence of noise on the effective deconvolutions for resolution. The paper presents the synthetic pseudoimpedance section constructed for various levels of noise added to seismic traces. The seismic traces are generated for seismogeological model. For the calculations of synthetic pseudoacoustic impedance a computer programme INVERS was used [3]. The programme consists of two main parts: (1) modelling, (2) visualisation of results.

Synthetic seismogram was calculated as a convolution of reflection coefficient series with seismic signal. The signal of Puzyriev $s(t)$ was applied

$$
s(t)=\exp \left(-\beta^{2} \cdot t^{2}\right) \cdot \sin \left(2 \pi f_{0} t \pm \varphi_{0}\right) .
$$

The parameters of signal are: $f_{0}$ - dominant frequency, $\varphi_{0}$ - initial phase, $\beta-$ dumping factor. The ratio $f_{0} / \beta$ determines the length of signal. When the ratio is 1 the signal is relatively short, the ratio 2 gives the long signal.

\section{RESULTS - MODELLING EXAMPLE}

A number of pseudoacoustic impedance sections for different signal parameters and noise were constructed in order to test the possibility of determining distribution of anhydrites in sections of pseudoacoustic impedance. A simplified seismological model presented in Fig. 1 is created on the basis of geological data from the Bytom Odrzański area.

Seismological model is related to thickness changes due to the dying-out of strata of anhydrite. Anhydrite inter-calculations in the rock salt deposits are visible on synthetic pseudoacoustic impedance sections when the seismic data is at low grade, distorted by noise and wave propagation phenomena, [2]. In practice, the reverse process is difficult, since the seismic data are always distorted by the noise.

The synthetic pseudoimpedance acoustics sections presented in this paper are constructed for different noise levels. The random noise $(10 \%, 20 \%$ and $30 \%)$ was added. The data have low $\mathrm{S} / \mathrm{N}$ ratio. Synthetic seismic sections were generated for signal with 
different dominant frequency $f_{0}(60 \mathrm{~Hz}$ or $40 \mathrm{~Hz})$. Two values of dumping factor $f_{0} / \beta=1$ and $f_{0} / \beta=2$ have been chosen for short and long signals, respectively. In some cases, a deconvolution is done before the inversion process to compare the resolution with and without deconvolution process. The time window between $0.75 \mathrm{~s}$ and $0.90 \mathrm{sec}$. contains especially interesting portion of seismic data of the salt deposits. In the figures presenting pseudoimpedance sections the colour scale is reflecting the relative velocity (or acoustic impedance) variations. The left scale is time [s]. The numbers of seismic traces are on the horizontal scale. Synthetic acoustic pseudoimpedance sections presented in Figs. 3, 4 are generated for short signal with low dominant frequency $f_{0}=40 \mathrm{~Hz}$.

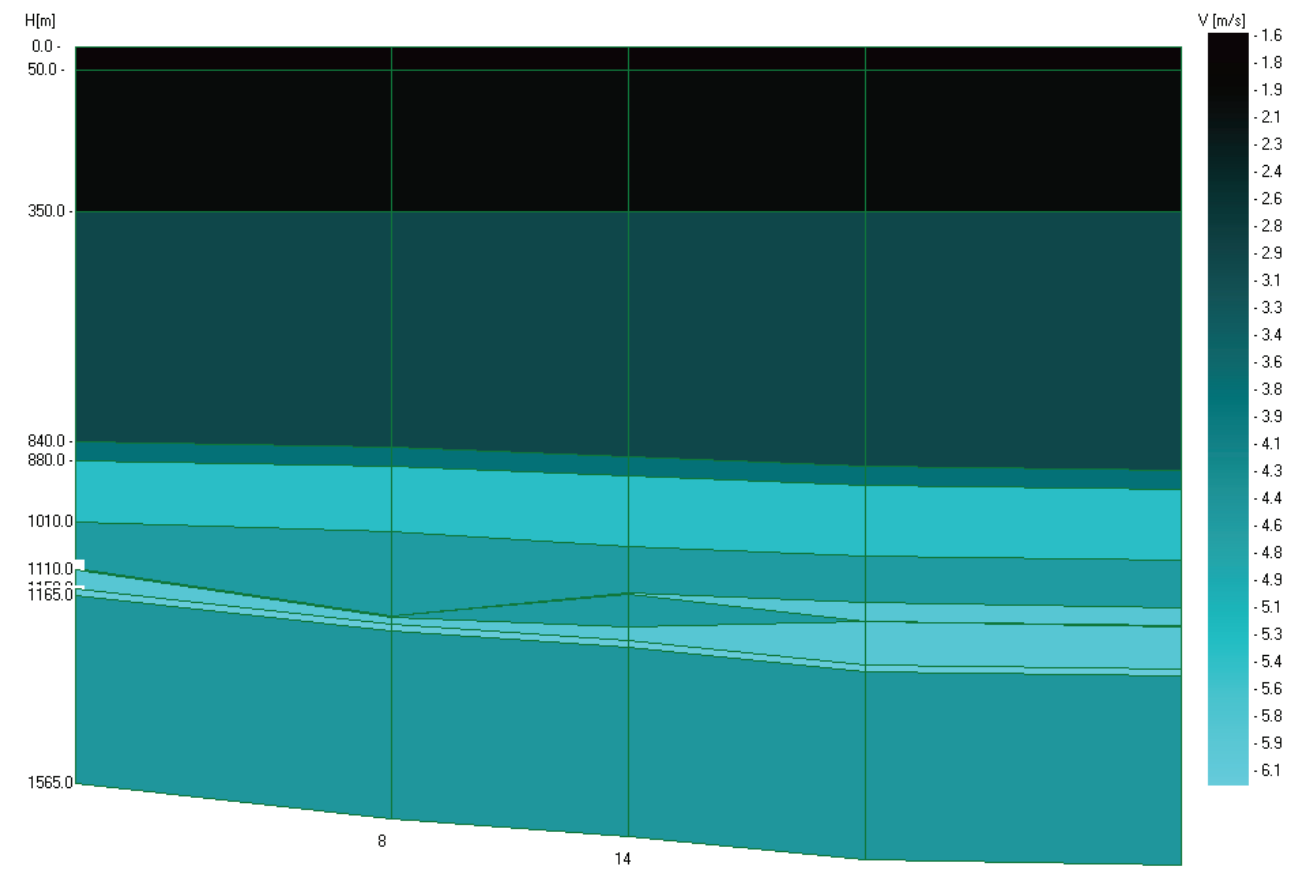

Fig. 1. Simplified seismological model I. Left vertical axis: depth in meters, horizontal axis: number of traces, right axis: wave velocity in $\mathrm{m} / \mathrm{s}$ displayed as colour scale

The anhydrite is completely invisible. The signal applied to construction synthetic pseudoimpedance acoustic section is short, level of noise low (10\%), but dominant frequency $f_{0}=40 \mathrm{~Hz}$ is too low. Synthetic pseudoimpedance acoustic section generated with the same signal parameters as in Fig. 2, but with process deconvolution included is presented in Fig. 3.

The deconvolution process done before inversion weakly increases the resolution, but pseudoimpedance acoustic section is rather hard to interpret. In the next figures, synthetic pseudoimpedance acoustic section generated with the signal dominant frequency $f_{0}=60 \mathrm{~Hz}$ is presented. 


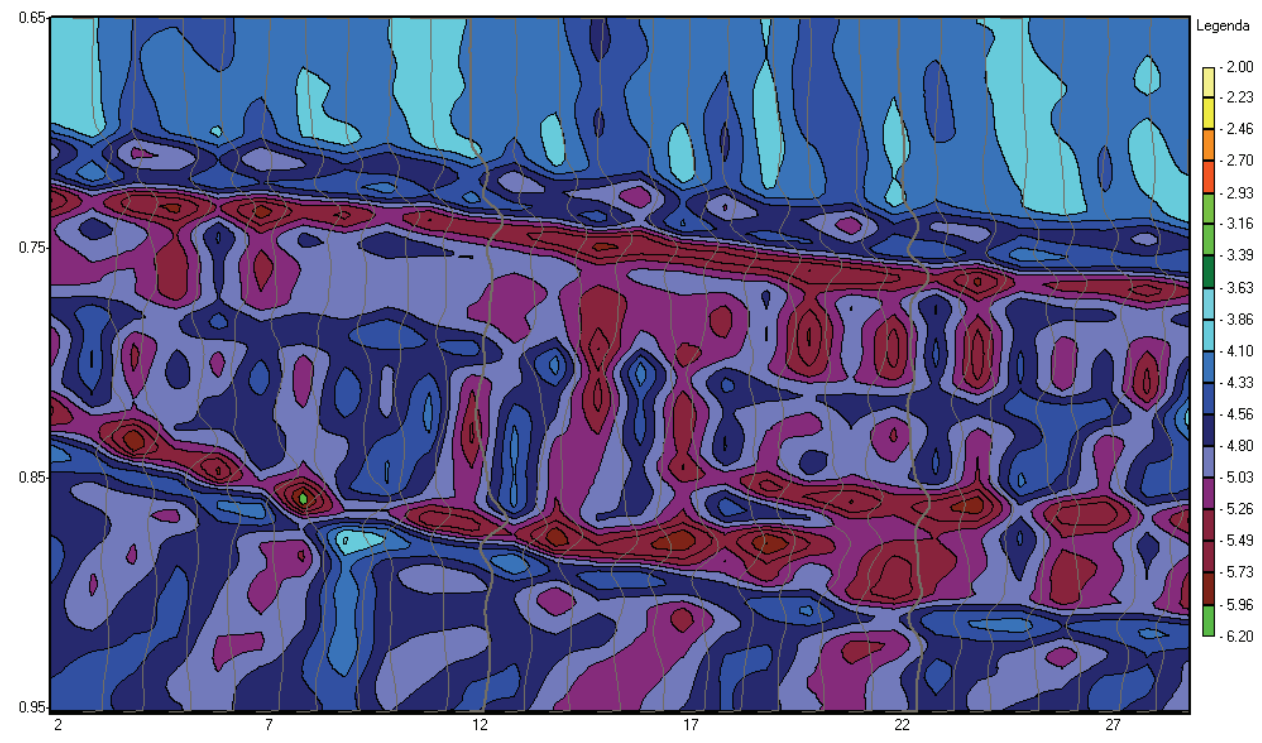

Fig. 2. Synthetic pseudoimpedance acoustic section; signal parameters: dominant frequency $f_{0}=40 \mathrm{~Hz}$, initial phase $\varphi_{0}=0$, dumping factor $f_{0} / \beta=1$, noise $10 \%$

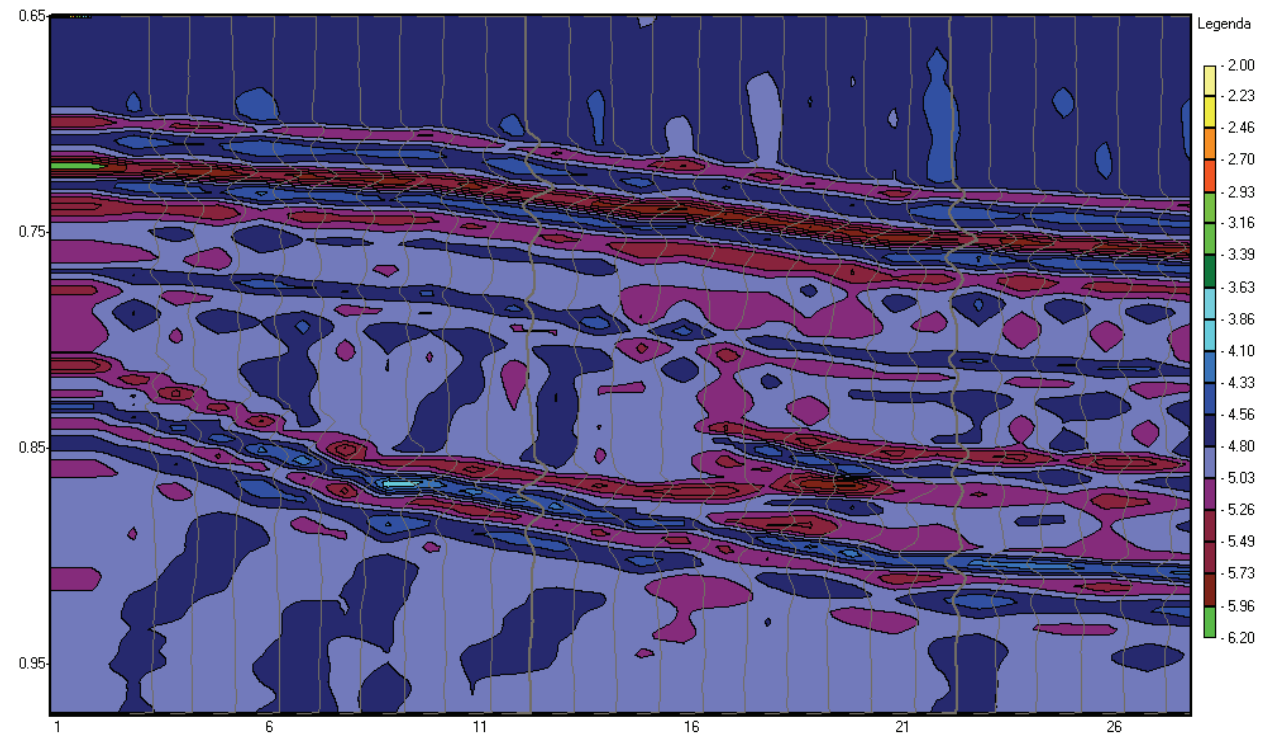

Fig. 3. Synthetic pseudoimpedance acoustic section with deconvolution; signal parameters: dominant frequency $f_{0}=40 \mathrm{~Hz}$, initial phase $\varphi_{0}=0$, dumping factor $f_{0} / \beta=1$, noise $10 \%$

The anhydrite is visible on synthetic pseudoimpedance acoustic section when the signal has dominant frequency $f_{0}=60 \mathrm{~Hz}$, dumping factor $f_{0} / \beta=1$ and $20 \%$ 
random noise added to seismic data. The resolution is higher when deconvolution is used.

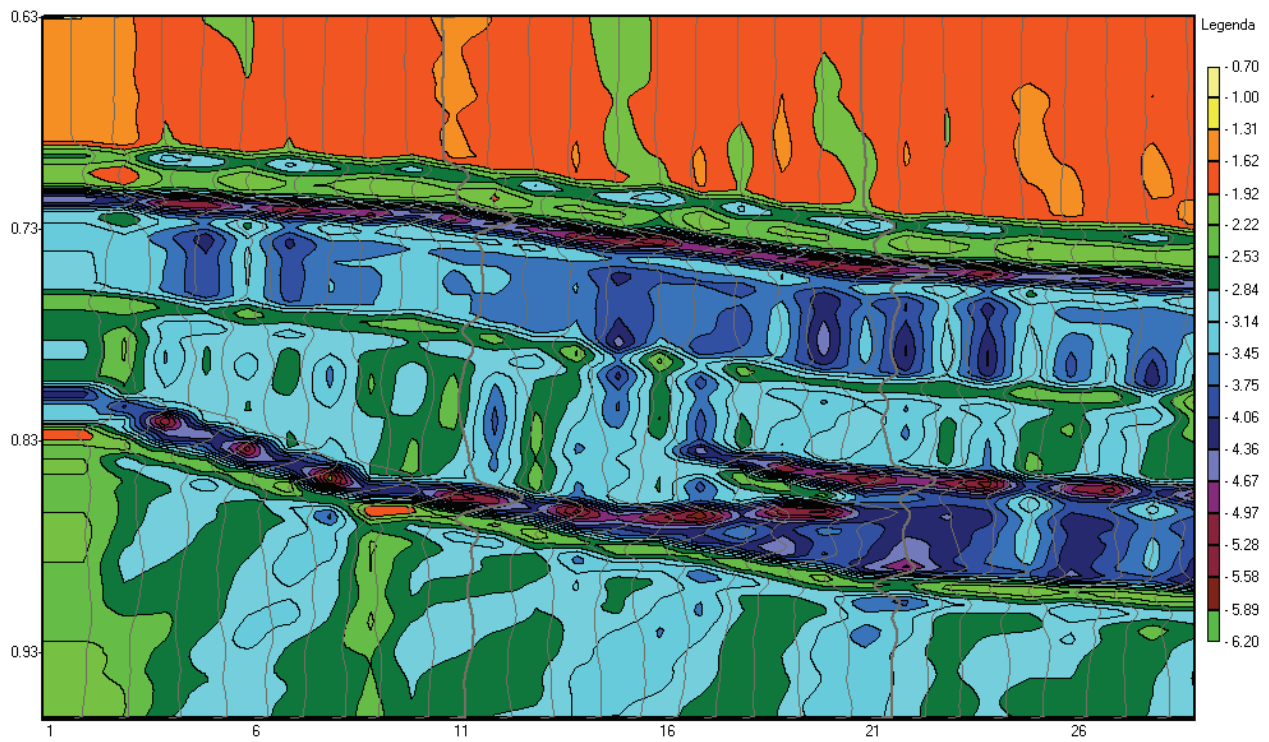

Fig. 4. Synthetic pseudoimpedance acoustic section; signal parameters:

dominant frequency $f_{0}=60 \mathrm{~Hz}$, initial phase $\varphi_{0}=0$, dumping factor $f_{0} / \beta=1$, noise $20 \%$

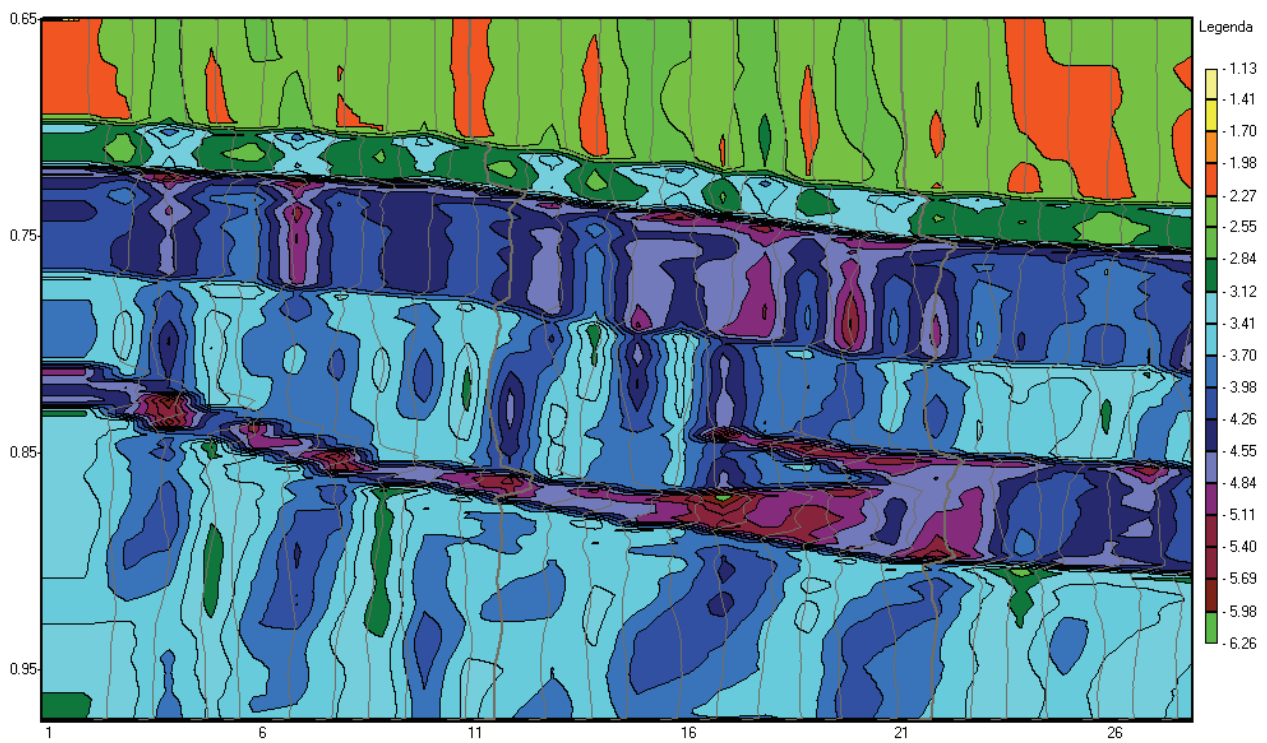

Fig. 5. Synthetic pseudoimpedance acoustic section after deconvolution; signal parameters: dominant frequency $f_{0}=60 \mathrm{~Hz}$, initial phase $\varphi_{0}=0$, dumping factor $f_{0} / \beta=1$, noise $20 \%$ 
In the next figures (Figs. 6,7) synthetic pseudoimpedance acoustic sections generated with the long signal, the same dominant frequency $f_{0}=60 \mathrm{~Hz}$ and noise are presented.

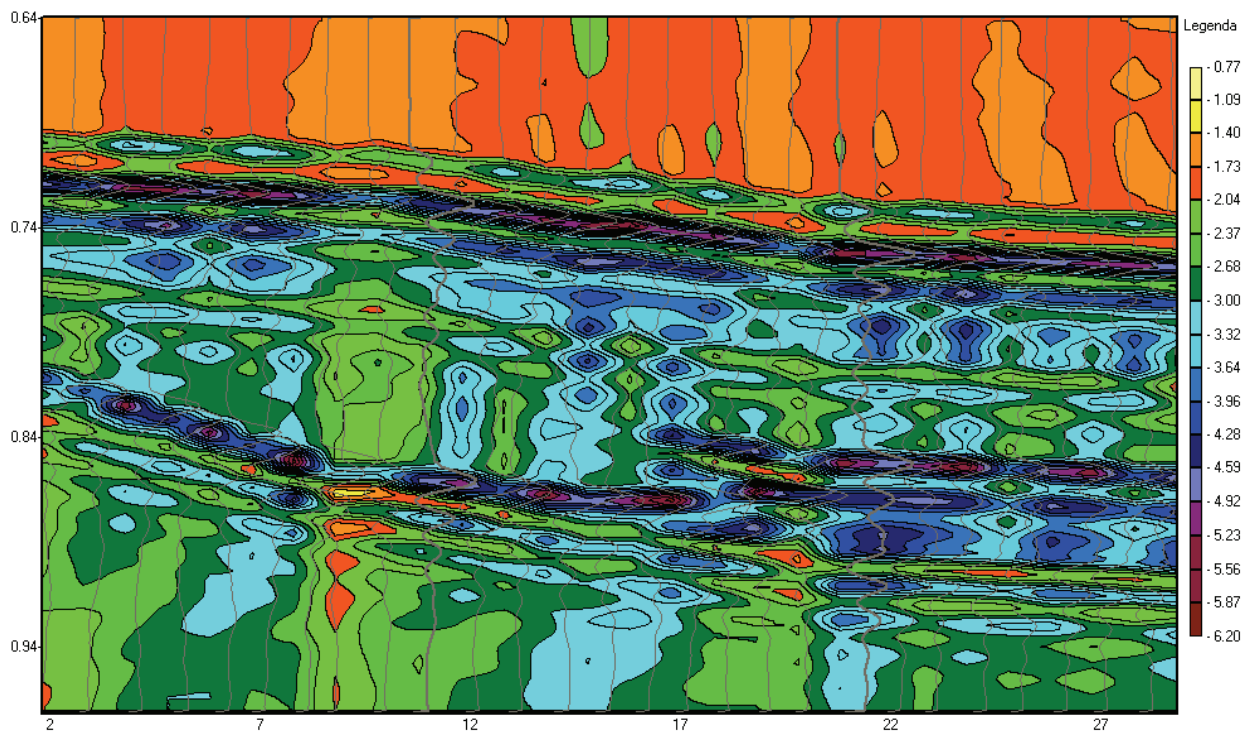

Fig. 6. Synthetic pseudoimpedance acoustic section; signal parameters:

dominant frequency $f_{0}=60 \mathrm{~Hz}$, initial phase $\varphi_{0}=0$, dumping factor $f_{0} / \beta=2$, noise $20 \%$

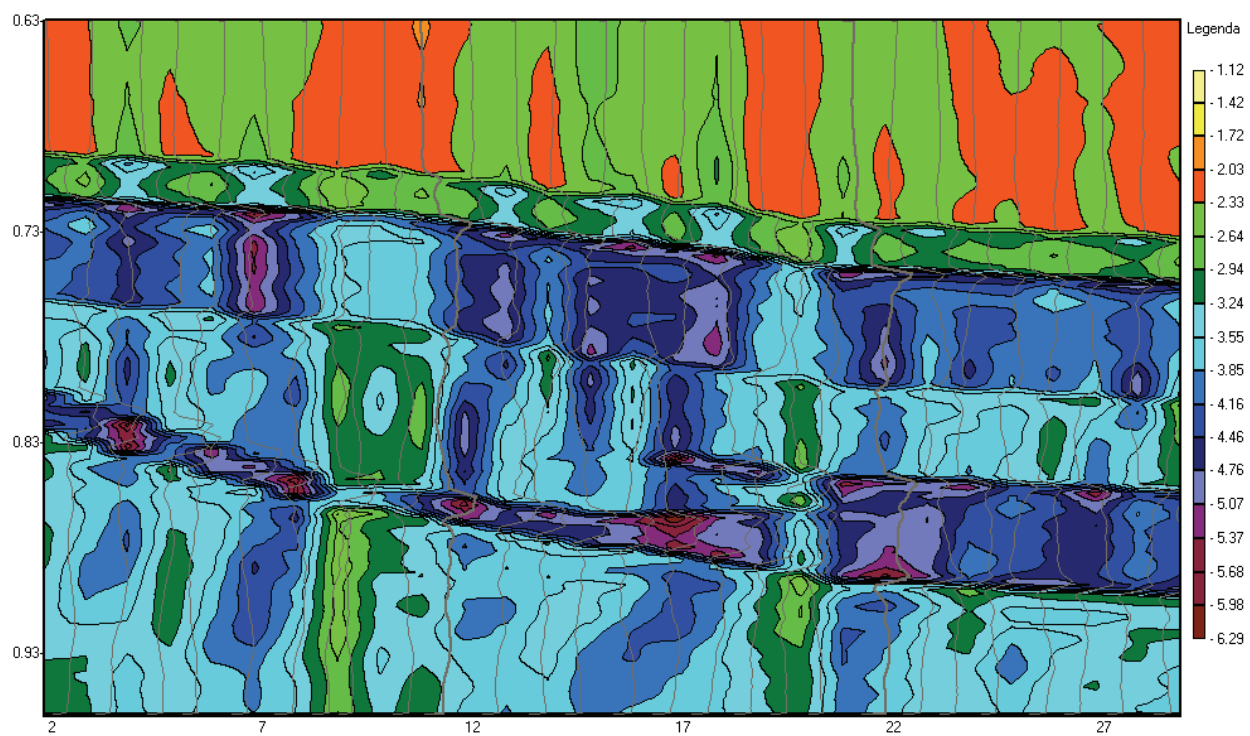

Fig. 7. Synthetic pseudoimpedance acoustic section after deconvolution; signal parameters: dominant frequency $f_{0}=60 \mathrm{~Hz}$, initial phase $\varphi_{0}=0$, dumping factor $f_{0} / \beta=2$, noise $20 \%$ 


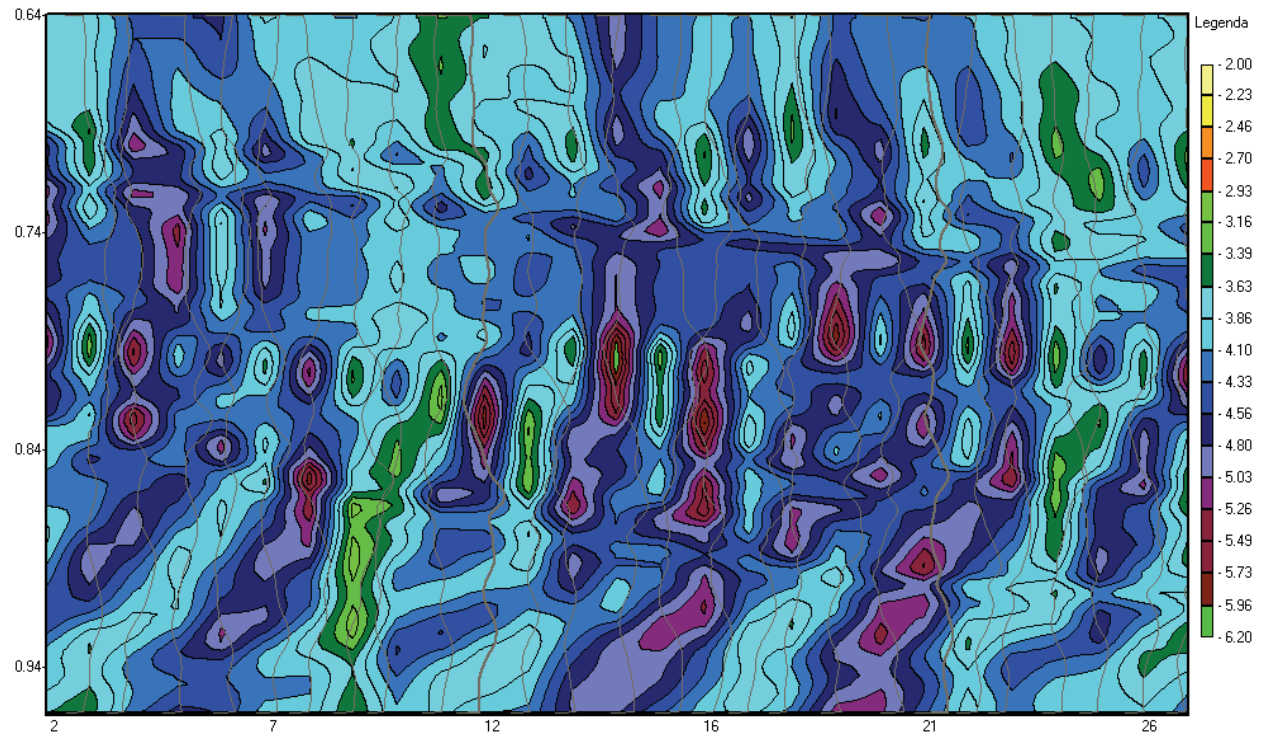

Fig. 8. Synthetic pseudoimpedance acoustic section; signal parameters: dominant frequency $f_{0}=60 \mathrm{~Hz}$, initial phase $\varphi_{0}=0$, dumping factor $f_{0} / \beta=2$, noise $30 \%$

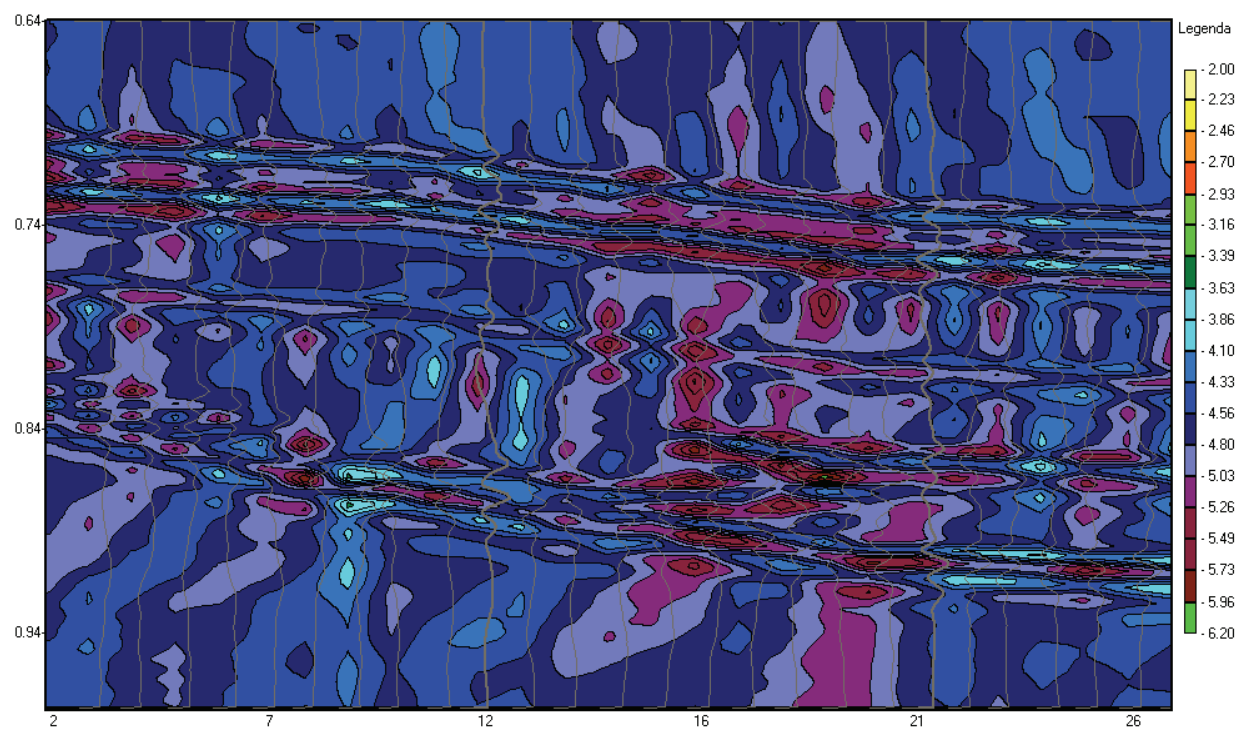

Fig. 9. Synthetic pseudoimpedance acoustic section after deconvolution; signal parameters: dominant frequency $f_{0}=60 \mathrm{~Hz}$, initial phase $\varphi_{0}=0$, dumping factor $f_{0} / \beta=2$, noise $30 \%$

Resolution of synthetic pseudoimpedance acoustic sections with deconvolution is visibly higher. In Figs. 8, 9, synthetic pseudoimpedance acoustic sections generated 
with the short signal - dumping factor $f_{0} / \beta=2$ the same dominant frequency $f_{0}=60 \mathrm{~Hz}$ and random noise $30 \%$ are presented.

The deconvolution process increases the resolution, but the synthetic pseudoimpedance acoustic sections generated with noise $30 \%$, even short signals are rather hard to interpret. When the sections are simulated for high noise and poor signal parameters - low dominant frequency and long seismic signal (the ratio $f_{0} / \beta \geq 2$ ), the quality can be sometimes insufficient for interpretation.

\section{SUMMARY}

Inversion is one of the means to extract additional information from seismic data. It effectively transforms seismic information into the geological domain, and thus, facilities the interpretation.

The analysis of synthetic pseudoimpedance acoustic sections presented above shows how for different cases the deconvolution is done before inversion process influences improvement of its quality. It is necessary to underline that when the sections are constructed for low signal to noise ratio $\mathrm{S} / \mathrm{N}$, specially when model simulates high noise and poor signal parameters - low dominant frequency and long seismic signal (the ratio $f_{0} / \beta \geq 2$ ), the effect can be sometimes insufficient especially for long signal and low signal to noise ratio $\mathrm{S} / \mathrm{N}$. In many cases deconvolution improves the resolution so may increase the accuracy and reliability of interpretation of pseudoimpedance acoustic section. The quality and quantity of interpretation of the final results increase with the bandwidth and dominant frequency increasing. Feasibility studies with synthetic modelling are recommended before embarking on inversion.

The work was supported by Geophysics Dept. AGH UST project (No. 11.11.140.769).

\section{REFERENCES}

[1] Kawalec-LataŁa E., Wpływ poziomu szumu na rozdzielczość sekcji pseudoimpedancji akustycznej w NW części LGOM, Górnictwo Odkrywkowe, 7/2007, 81-86.

[2] Kawalec-Latala E., Detection of salts deposits geometry variation AGH, Journal of Mining and Geoengineering, Vol. 36, No. 2, 2012, 161-169.

[3] KaWALEC-LATAŁa E., The influence of seismic wavelet on the resolution of pseudoimpedance section for construction of underground storage, Gospodarka Surowcami Mineralnymi (Mineral Resources Management), Vol. 24, No. 2/3, 2008, 387-397.

[4] KAWALEC E., Inwersja sejsmiczna w rozpoznawaniu niejednorodności złóż soli perspektywicznych dla budowy podziemnych zbiorników, Wydawnictwa AGH, Kraków, 2009.

[5] ROBINSON E., A Seismic Inversion and Deconvolution, Geophysika Press, London-Amsterdam, 1984.

[6] Veeken P.C.H., Da Silva M., Seismic inversion methods and some of their constraints, First break, Vol. 22, 2004, 47-70. 